This is an author produced version of a paper published in Ecosystems. This paper has been peerreviewed and is proof-corrected, but does not include the journal pagination

Citation for the published paper: de la Riva E.G., Vioelle C., Pérez-Ramos I.M, Marañon T., Navarro-Fernández C., Olmo M., Villa R. (2017) A multidimensional functional trait approach reveals the imprint of environmental stress in Mediterranean woody communities. Ecosystems. https://link.springer.com/article/10.1007/s10021-017 $-0147-7$

Access to the published version may require journal subscription. Published with permission from:

Springer 


\title{
A multidimensional functional trait approach reveals the imprint of environmental stress in Mediterranean woody communities
}

\author{
Enrique G. de la Riva ${ }^{1 *}$, Cyrille Violle ${ }^{2}$, Ignacio M. Pérez-Ramos ${ }^{3}$, Teodoro Marañón ${ }^{3}$, \\ Carmen M. Navarro-Fernández ${ }^{3}$, Manuel Olmo ${ }^{1}$, and Rafael Villar ${ }^{1}$
}

${ }^{1}$ Área de Ecología, Facultad de Ciencias, Universidad de Córdoba, 14071 Córdoba, Spain.

${ }^{2}$ CEFE UMR 5175, CNRS - Université de Montpellier - Université Paul-Valéry Montpellier - EPHE 1919 route de Mende, FR-34293 Montpellier, Cedex 5, France.

${ }^{3}$ Instituto de Recursos Naturales y Agrobiología de Sevilla, IRNAS, CSIC, 41012 Seville, Spain.

\begin{abstract}
Water availability is one of the most important factors determining species distribution, plant community structure and ecosystem functioning. We explore how the functional structure of Mediterranean woody plant communities varies along a regional gradient of aridity in the Andalusian region (south Spain). We question if communities located in more arid sites show more similarity in their functional structure when compared with communities located in wetter sites or if, instead, there is divergence in their functional spaces. We selected five aridity zones (three sampling sites per zone) and measured 13 traits of different functional dimensions (including leaf, stem and root traits) in 74 woody plant species. We quantified functional space differences using the n-dimensional niche space approach (hypervolume). We found a larger functional space for the wetter communities compared with the more arid communities, which showed greater overlap of the trait space occupation. Our results indicate that aridity acts as a key abiotic filter affecting various metrics of the community trait structure, in accordance with the plant economics spectrum. We have also documented consistent variation in the functional space, supporting lower functional diversity under more harsh climatic conditions. The trend of functional space variation along the aridity gradient was different when considering traits from only one plant organ. Thus, the filtering process driving the functional structure of the communities studied here largely depends on the trait axis considered; for example, the root dimension showed considerable variation in wet environments whereas the leaf dimension exhibited a larger functional space in the drier habitats.
\end{abstract}

Keywords: Aridity, dry shrubland, functional diversity, functional structure, hypervolume, plant traits. 


\section{Introduction}

Trait-based approaches have proved fruitful to understand biodiversity effects on ecosystem processes and underlying physiological mechanisms (Mason and others 2005; Grime and others 2006; Garnier and others 2007; Mouillot and others 2011). However, they have been applied mostly in experimental conditions or along local environmental gradients (Bernard-Verdier and others 2012; Maire and others 2012; de la Riva and others 2016a). This impedes a thorough evaluation of ecosystem functionality along large-scale environmental gradients, a high priority for functional biogeography (Violle and others 2014). A notable exception refers to global modelling studies that classify ecosystems based on functional type diversity (Kleidon and Mooney 2000) and sometimes on plant functional traits (Heberling and Fridley 2012). However, these models typically refer to database approaches in which the real flora or trait plasticity is largely ignored. In other words, woody communities of a given biogeographic area are commonly described by a similar set of plant functional trait values without taking into account the species composition or intraspecific trait variation. In addition, the ecological strategies seem to be highly scale-dependent (Lamanna and others 2014; de la Riva and others 2016b), with functional strategies identified at smaller spatial scales not necessarily matching the patterns found at regional or global levels (Mokany and Roxburgh 2010; Funk and Cornwell 2013). Thus, there is an urgent need for a functional understanding of ecosystem variability at larger spatial scales, which would provide potential insights into both ecosystem and global change biology.

A trait-based approach is a relevant tool to evaluate plant responses to environmental changes since a given trait can be related straightforwardly to abiotic or biotic constraints (Garnier and Navas 2012). However, the application of this approach to plant communities has been challenged recently (Laughlin 2014; Lamanna and others 2014) based on the idea that, instead of using single traits, studying whole-phenotype responses is more useful to understand the filtering effects of environmental factors on natural communities (Laughlin 2014; Carmona and others 2016). The use of trait information of the different plant organs (leaves, stems, roots and seeds), however may offer complementary information on plant functional responses to the environment (Laughlin 2014). In this regard, root traits have been generally overlooked in studies of functional structure (i.e. the composition and diversity of functional traits; Mouillot and others 2011), despite the important role of root attributes in several key ecosystem processes (Craine and others
2003). Although there is a growing interest in investigating the role of root traits on plant community assembly (e.g. Laughlin and others 2010; PérezRamos and others 2012; Kramer-Walter and others 2016; Navarro-Fernández and others 2016), the belowground compartment has been particularly ignored in studies at large spatial scales. For example, root trait data represent only $7 \%$ of the TRY database with respect to the leaf compartment (Laliberté 2017). Thus, given the multi-dimensionality of plant functions, the lack of consideration of several key functional traits, such as those related to belowground functioning, may strongly bias our estimation of community functional structure and diversity (Laughlin 2014).

Functional biodiversity changes have been frequently assessed using diversity indices that take into account different dimensions (Mason and others 2005; Villéger and others 2008): the range of functional trait variability in a given species assemblage (functional richness), the evenness of abundance distribution across species traits (functional evenness), and the divergence in the abundance distribution of functional traits (functional divergence). An alternative and recent approach to quantify the magnitude of the occupied functional space is the ndimensional niche space method (Blonder and others 2014), based on the Hutchinson's multidimensional niche concept (Hutchinson 1957). Hutchinsonian niches are related with functional diversity and allow us to quantify niche spaces by assessing the functional trait hypervolumes that characterise the phenotypic spaces occupied by a set of species (Lamanna and others 2014). One of the main advantages of this method is that it can accurately measure the volume of a high-dimensional shape that may include holes or other complex geometrical features, which refine the measurement of the functional space better than linear and continuous dimensions (i.e. the convex hull model; Cornwell and others 2006). Also, the hypervolume algorithm permits measurement of the proportions of the hypervolumes that share the same functional space (see details in Material and Methods). Thus, the n-dimensional space makes it possible to predict functional redundancy within communities (overlap) as a result of the convergence towards a relatively small set of successful trait combinations (Grime 2006; Díaz and others 2016); or plant divergence and character displacement (the portion of unique hypervolume) as the result of niche shifts among species along environmental gradients (Violle and Jiang 2009). Therefore, it may allow inferring relevant processes such as competitive exclusion and niche differentiation (see Blonder and others 2014; Loranger and others 2016a). However, despite its great potential to provide a better understanding of the rules that govern 
the process of community assembly, the approach based on hypervolume has been barely used in plant community studies (but see Lamanna and others 2014, Loranger and others 2016a).

In arid and semi-arid regions, water availability is one of the main limiting resources for plants (Padilla and Pugnaire 2007), affecting many aspects of plant fitness and therefore of species composition and distribution (Bréda and others 2006; Engelbrecht and others 2007). Arid conditions promote specific adaptations to the imposed climatic constraints, reflecting different functional trade-offs between nutrient acquisition, growth or life span (Reu and others 2011). Thus, communities in dry environments tend to be dominated by short, slow-growing species with higher tissue dry matter content and higher water-use efficiency, which is known as a conservative resource-uptake strategy (Wright and others 2004; Grubb and others 2015; de la Riva and others 2016a). In contrast, highlyproductive ecosystems are dominated by plant communities with tall, fast-growing species with a large absorption surface per unit of tissue biomass (high specific leaf area and specific root area values) and high photosynthetic capacity (high nitrogen or chlorophyll concentration), indicating an acquisitive resource-uptake strategy (Wright and others 2004; de la Riva and others 2016b). However, in spite of this general tendency in resource uptake strategies, some evidence suggests that different factors are able to drive opposite assembly processes for related traits (Mason and others 2011).

It has long been observed that the diversity of plant functional strategies (i.e. functional diversity) at a global scale is largely conditioned by climate (Kleidon and Mooney 2000; Thuiller and others 2006), likely because this is one of the main factor which determines resource availability (Schimel and others 1996; Arnell 1999). According to theory, greater functional diversity is expected in

Table 1. List of the 13 functional traits measured in this study, their abbreviations, units and main role in plant functioning.

\begin{tabular}{|c|c|c|c|c|}
\hline Group & Trait & Abbreviation & Unit & Functional role \\
\hline \multirow{3}{*}{$\begin{array}{l}\text { Leaf } \\
\text { morphology }\end{array}$} & Leaf size & Lsize & $\mathrm{cm}^{2}$ & \multirow{3}{*}{$\begin{array}{l}\text { Light capture and growth rate } \\
\text { Light capture and growth rate } \\
\text { Physical resistance and stress } \\
\text { tolerance }\end{array}$} \\
\hline & Specific leaf area & SLA & $\mathrm{m}^{2} \mathrm{~kg}^{-1}$ & \\
\hline & Leaf dry matter content & LDMC & $\mathrm{g} \mathrm{g}^{-1}$ & \\
\hline \multirow{2}{*}{$\begin{array}{l}\text { Stem } \\
\text { morphology }\end{array}$} & Stem dry matter content & SDMC & $\mathrm{g} \mathrm{g}^{-1}$ & \multirow{2}{*}{$\begin{array}{l}\text { Resistance to physical hazards } \\
\text { Physical resistance, growth } \\
\text { rate and stress tolerance }\end{array}$} \\
\hline & Stem wood density & SWD & $\mathrm{g} \mathrm{cm}^{-3}$ & \\
\hline \multirow{3}{*}{$\begin{array}{l}\text { Root } \\
\text { morphology }\end{array}$} & Specific root length & SRL & $\mathrm{m} \mathrm{g}^{-1}$ & \multirow{3}{*}{$\begin{array}{l}\text { Water and nutrients } \\
\text { acquisition } \\
\text { Resistance to physical hazards } \\
\text { Physical resistance, growth } \\
\text { rate and stress tolerance }\end{array}$} \\
\hline & Root dry matter content & RDMC & $\mathrm{g} \mathrm{g}^{-1}$ & \\
\hline & Root tissue mass density & TMDr & $\mathrm{g} \mathrm{cm}^{-3}$ & \\
\hline \multirow{2}{*}{ Plant Size } & Plant height & Pheight & $\mathrm{m}$ & \multirow{2}{*}{$\begin{array}{l}\text { Dispersal distance, light } \\
\text { capture, aboveground } \\
\text { competition } \\
\text { Dispersal distance, light } \\
\text { capture, aboveground } \\
\text { competition }\end{array}$} \\
\hline & Plant cover & Pcover & $\mathrm{m}^{2}$ & \\
\hline \multirow{4}{*}{$\begin{array}{l}\text { Leaf } \\
\text { Chemical }\end{array}$} & $\begin{array}{l}\text { Leaf nitrogen } \\
\text { concentration }\end{array}$ & LNC & $\%$ & \multirow{4}{*}{$\begin{array}{l}\text { Light capture and } \\
\text { photosynthetic rate } \\
\text { Light capture and } \\
\text { photosynthetic rate } \\
\text { Gas exchange and water-use } \\
\text { efficiency }\end{array}$} \\
\hline & & & & \\
\hline & Leaf chlorophyll $^{1}$ & LChl & $\mu \mathrm{g} \mathrm{g}^{-1}$ & \\
\hline & Isotopic carbon fraction & $\delta^{13} \mathrm{C}$ & $\%$ & \\
\hline
\end{tabular}




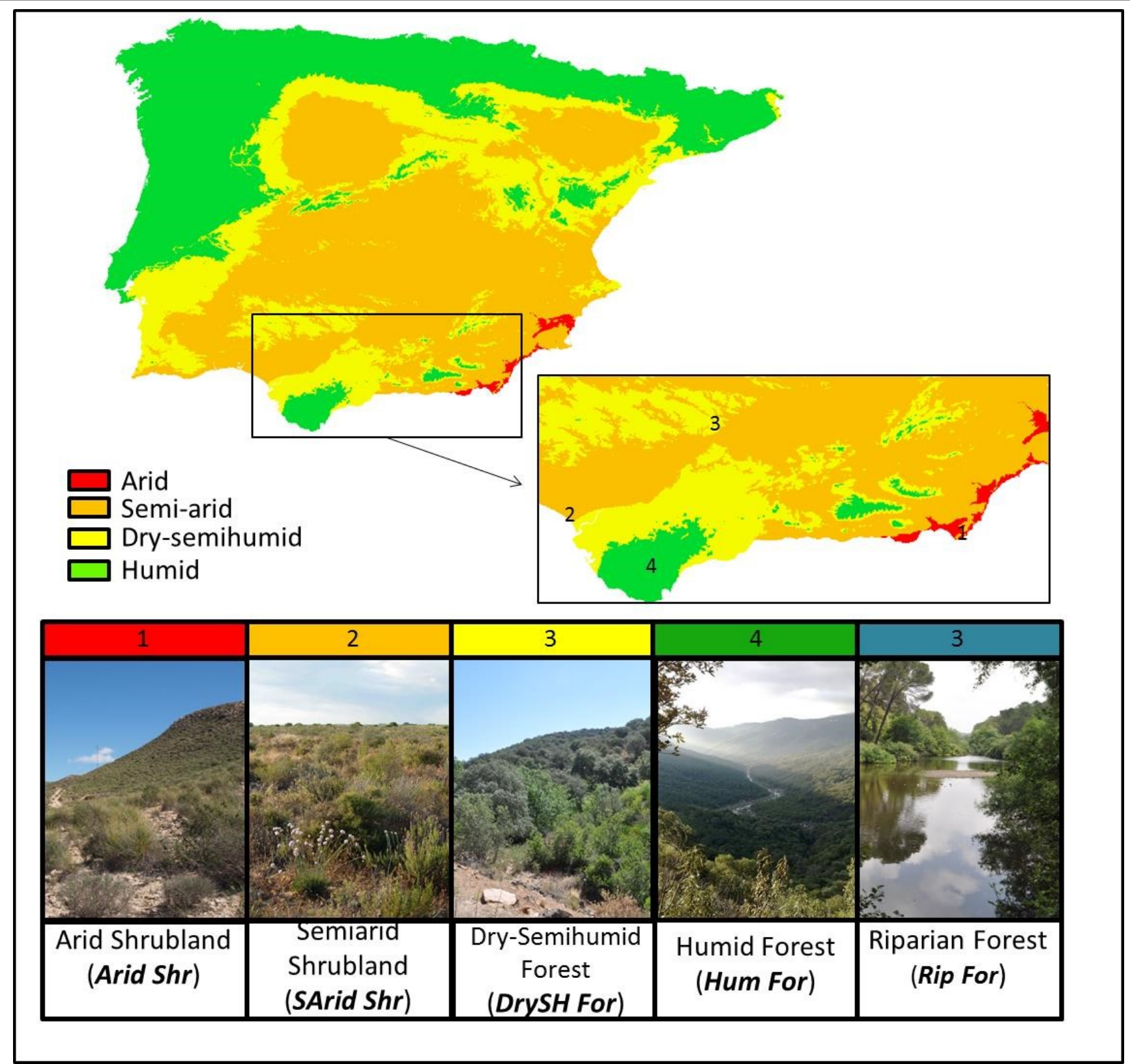

Figure 1. Location of the study zones (and their abbreviations) selected along the regional aridity gradient. The aridity index map was generated in ArcGis software 10.2 (Trabucco and Zomer 2009).

resource-rich and productive environments (Heywood 1995) as a result of strong interspecific competition, which promotes resource partitioning (limiting similarity hypothesis; MacArthur and Levins 1967). By contrast, in environments that are more resource-limited, plant adaptations to such stressful conditions are limited, constraining the phenotypic space and decreasing the plant functional diversity (Jacobsen and others 2008). However, and contrary to this general global pattern, some studies at lower scale have shown lower diversity (for both species and functional richness) in moreproductive environments (Grime 2006; Pakeman 2011; de Bello and others 2013, Loranger and others 2016b). These apparently contradictory results may be explained because climate imposes constraints on a certain range of parameter values (Kleidon and Mooney 2000), but within the range of viable solutions for a particular environment the diversifi- cation of successful strategies exists (de la Riva and others 2016b). Thus, there is a need to understand how arid conditions determine the functional structure and niche space volume of plant communities, and to test the initial hypothesis stating that the niche functional space of communities located at more arid sites is smaller than the hypervolume of communities inhabiting wetter sites.

In this paper, we explore a regional gradient of well -preserved Mediterranean woody plant communities, from dry to permanently-wet conditions, covering a wide natural area of water conditions in southern Spain. We measured a large set of plant traits, including root traits, representing the main functional dimensions of the vegetative phenotype. Using the n-dimensional niche space approach, we examined specifically: i) whether, and to what extent, the functional trait structure of different communities is sensitive to the regional aridity gradient; in particu- 
lar, whether the communities exposed to harsher (drier) environmental conditions display smaller hypervolumes; and ii) whether the patterns obtained for all traits are congruent with the hypervolumes calculated for each independent dimension of the phenotype (i.e. leaf and root morphology or leaf chemical composition).

\section{Material and methods}

\section{Study area}

The study was conducted in five Mediterranean zones, dominated by woody plant communities (forests and shrublands) and located in Andalusia, southern Spain $\left(87597 \mathrm{~km}^{2}\right.$ ), that encompass a wide range of precipitation (from 200 to $2000 \mathrm{~mm}$ year $^{-1}$; Fig. 1). To characterize the water availability of the different zones we use the Aridity index (Fig. 1), based on the ratio of Mean Annual Precipitation and Mean Annual Potential Evapo-Transpiration, using the datasets from the CGIAR consortium for spatial information (http://www.cgiar-csi.org/). According to the Global-Aridity datasets (Trabucco and Zomer 2009) the studied zones can be classified as follows: i) Arid zone at Cabo de Gata Natural Park, dominated by shrubs (e.g. Anthyllis cytisoides, Helianthemum almeriensis) (hereafter Arid Shr); ii) Semi-Arid zone at Doñana National Park, dominated by shrubs on sandy soils (e.g. Halimium commutatum, Stauracanthus genistoides) (hereafter $\boldsymbol{S} \boldsymbol{A}$ rid Shr); iii) Dry-Semihumid zone in the Sierra Morena mountains, dominated by forest with droughttolerant evergreen species (e.g. Quercus ilex, Rosmarinus officinalis) (hereafter DrySH For); iv) Humid zone at Los Alcornocales Natural Park, dominated by mixed forests of evergreen oaks (Quercus suber) and winter-deciduous oaks (Quercus canariensis) (hereafter Hum For); and v) Riparian Forest (hereafter Rip For) near the Guadiato River (Sierra Morena mountains, close to the DrySH For zone), with permanent water availability due to its proximity to a river channel and dominated by deciduous tree species (e.g. Fraxinus angustifolia, Ulmus minor). For simplicity we will refer to these five studied zones throughout the article using the acronyms.

\section{Sampling design}

Three sampling sites with a low anthropogenic influence and similar bedrock were selected (no more than $10 \mathrm{~km}$ between them) per each aridity zone. Four 20-m-long transects were set up randomly in each of the sampling sites, with a minimum distance of $10 \mathrm{~m}$ relative to one another and avoiding steep slopes. The area sampled in each of the five zones or habitat types was around $1800 \mathrm{~m}^{2}\left(600 \mathrm{~m}^{2}\right.$ per sampling site). Species composition and abundances were recorded using the "line interception method" (Canfield 1941). The cover of all woody individuals was estimated by identifying plants intercepted by a metric tape and recording intercept distances in each of the four 20-m transects (total abundance can exceed $20 \mathrm{~m}$ since the overlapping vegetation layers were taken into account). The mean relative abundance for each species and sampling site was calculated as the mean value of the four transects.

\section{Trait measurements}

For trait measurements, we selected all the species appearing in the transect excluding only those with a relative abundance below $0.5 \%$ since in these cases it was difficult to find at least six individuals per species in the sampling sites (12 species were excluded in total). This led to a total of 74 selected woody plant species, many of them occurring in more than one study zone (Appendix S1).

Healthy adults of the woody plant species were selected randomly during the peak of plant biomass (spring). We measured 13 key functional traits related to morphology (of leaf, stem and root), physiology (leaf chemical compounds) and plant size, covering the main plant functional dimensions (see functional roles in Table 1). All these trait measurements were carried out according to the criteria defined by Pérez-Harguindeguy and others (2013), varying the number of replicates per species and zone, for plant size (10), leaf traits (6), root traits (4), and chemical traits (1 combined value) according to trait variability and logistic limitations (the plant replicates were distributed among the three sampling sites per zone, wherever possible). For a detailed protocol of sample harvesting and trait measurements see de la Riva and others (2016a).

Leaf morphological traits.- Six individuals per species and aridity zone were chosen, on which the following leaf traits were measured: leaf size (Lsize); specific leaf area (SLA; leaf area per unit of leaf dry mass); and leaf dry matter content (LDMC; leaf dry mass per unit of water-saturated leaf fresh mass).

Stem morphological traits.- On the same six individuals per species and aridity zone, we measured the following stem traits: stem dry matter content (SDMC), which was obtained as the ratio between dry and saturated fresh mass; and stem wood density (WD), calculated as the stem dry mass divided by its fresh volume (which was calculated according to the Archimedes principle, i.e., measuring the volume of water displaced by the immersion of the stem).

Root morphological traits.- The fine roots $(<$ 
$2 \mathrm{~mm}$ in diameter) of four individuals per species and aridity zone were used to measure belowground traits: specific root length (SRL, root length per unit of root dry mass), root dry matter content (RDMC, root dry mass per unit of water-saturated root fresh mass) and root tissue mass density (TMDr, root dry mass per root volume). The root area and root volume data were obtained by analysing the scanned root samples with WinRHIZO 2009 (Regent Instruments Inc., Quebec, Canada).

Plant size traits.- Plant height (Pheight) and cover (Pcover; canopy projection) were measured as functional traits commonly used to quantify plant size. Measurements were made using a metric tape on ten individuals per species (excepting some rare species, for which only six individuals were found, such as Crataegus monogyna in Sierra Morena, Withania frutescens in Cabo de Gata or Phillyrea latifolia in Alcornocales). For tall trees, plant height was estimated using the 'Christen height' meter, based on trigonometric principles (Klein 2007).

Leaf physiological and chemical traits.Three chemical traits related to plant physiology were measured: leaf nitrogen concentration (LNC), leaf chlorophyll (LChl, the concentration of chlorophyll per unit of fresh leaf mass) and leaf carbon isotopic ratio $\left(\delta^{13} \mathrm{C}\right)$. LNC and LChl were measured on leaves of six individuals per species and aridity zone, whereas the $\delta^{13} \mathrm{C}$ was analysed in a mixture of leaves from six different individuals per species and aridity zone.

\section{Data analyses}

To study the degree of trait variation and the correlations among them a general principal components analysis (PCA) was performed with the whole set of traits (13 variables) and for the 91 observations of woody plants (74 species, but some of them occurring in more than one zone). To explore differences in functional structure between the communities from the five aridity zones, we used a linear mixed model to calculate the differences among aridity zones for each trait, using species-mean trait values per zone (considering species as the random effect), followed by post hoc multiple pairwise comparisons (Tukey's test). Variables were log-transformed when necessary.

The total niche space of the community was calculated by the estimation of the n-dimensional hypervolume (Blonder and others 2014), from the trait space occupied by the total pool of species that were present in each aridity zone. In order to reduce the number of dimensions (which is recommended for this analysis), we first performed a PCA for each dimension (leaf, stem and root morphology, leaf chemical and plant size) separately. With the first PC axis of each dimension (which explained between 53 and $95 \%$ of the variation; see more details in the results section), we calculated the hyper- volume for each aridity zone using a multidimensional kernel density estimation (KDE) procedure (see Blonder and others 2014 for mathematical details). The units of the hypervolumes are reported as the standard deviations of centred and scaled logtransformed trait values, raised to the power of the number of trait dimensions used ( $\left.\mathrm{sd}^{\text {number of dimensions }}\right)$. We also calculated the overlap between the hypervolumes of each aridity zone with the correlation analysis of the "hypervolume" package, which compares the similarity between hypervolumes using the Sørensen index (intersection hypervolume divided by mean hypervolume for each pair of assemblages; see Blonder and others 2014). In addition, to observe if the functional trait overlap between aridity zones was related to species similarity, we also calculated the Sørensen index of similarity for species composition between each pair of aridity zones. A rarefaction analysis was performed to control for the effects of species richness on the hypervolume. Thus, for each zone, we built 100 randomised communities composed of species drawn (12 species) from the species pool of that aridity zone. Then, we calculated the hypervolume of each sample and performed a one-way ANOVA to compare the hypervolumes of the zones independently of species richness.

For a comparative purpose, we also calculated the three functional diversity indexes (FRich: functional richness; FEve: functional evenness; and FDiv: functional divergence) proposed by Mason and others (2005) and Villéger and others (2008). For that we used the loadings of the first PCA axis of each dimension (leaf, stem and root morphology, leaf chemical and plant size) in each sampling site (3 sampling sites per aridity zone). The functional richness reflects the amount (the difference between the maximum and minimum values) of functional trait variability in a given community. The functional evenness quantifies the equitability of abundance distribution across species trait values. The functional divergence captures the degree of differentiation in the abundance distribution of species functional traits (for more details see Mason and others 2005, Villéger and others 2008). We performed a one-way ANOVA and post hoc multiple pairwise comparisons (Tukey's test) to compare functional diversity indexes between aridity zones.

Next, in order to examine whether the hypervolume variations were consistent for different functional dimensions, we performed the same analysis for each dimension separately: leaf morphological (Lsize, SLA and LDMC), root (SRL, RDMC and TDMr) and leaf chemical traits (LNC, LChl and $\left.\delta^{13} \mathrm{C}\right)$. We also performed the rarefaction analysis for each of these dimensions. Since the hypervolume analysis needs at least three variables, the stem and plant-size dimensions (with only two traits each) were discarded for these specific analyses. 

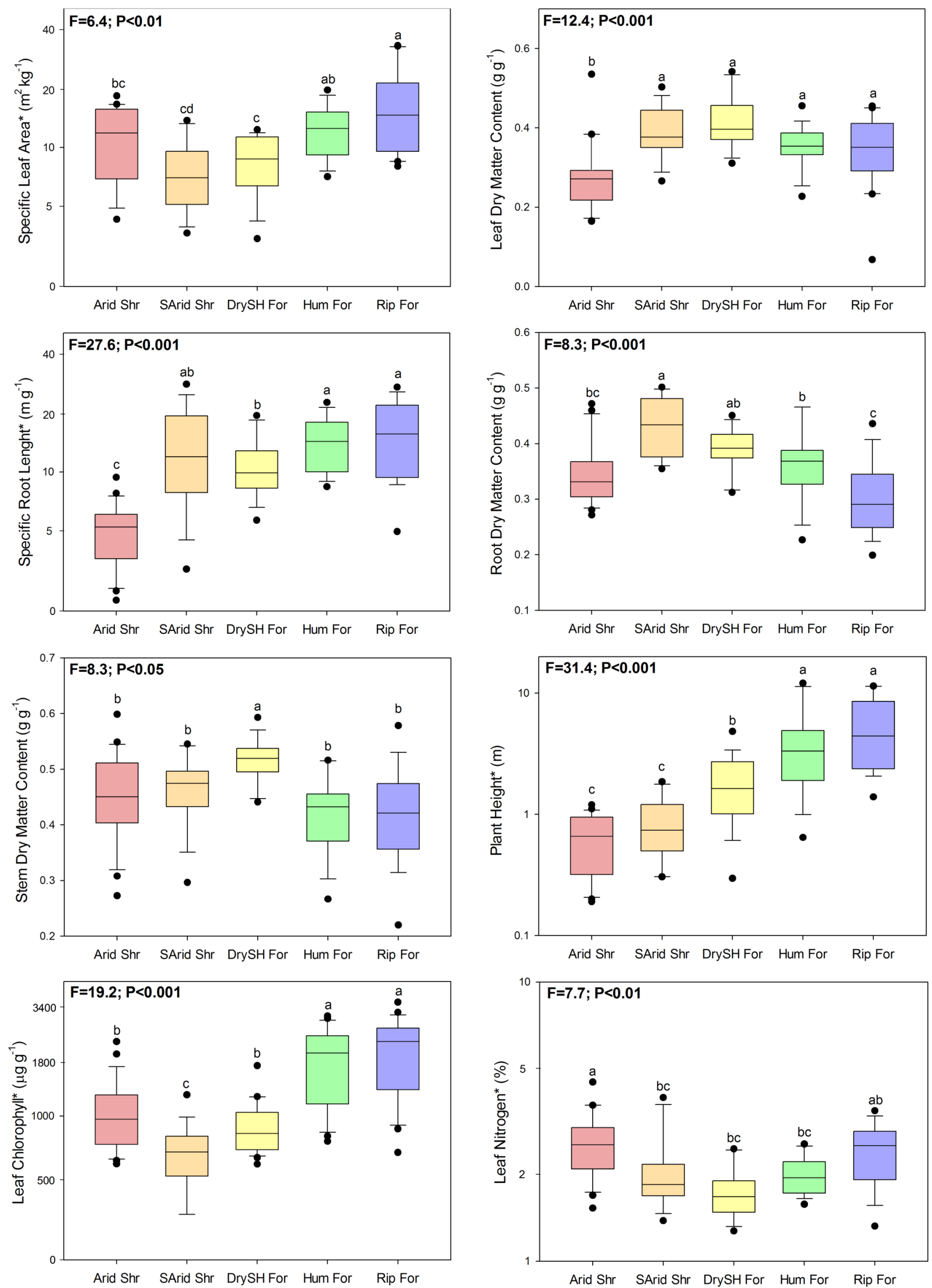

Figure 2. Average values for eight of the measured 13 functional traits in each aridity habitat. Box-plot of functional trait composition between habitats, calculated considering all the species sampled in each habitat. The line inside the box represents the median value, the box limits are the 25 th and 75 th percentiles, error bars show 10th and 90th percentiles, and filled symbols show outliers. Different letters indicate significant differences $(\mathrm{P}<0.05)$ between habitats. Some traits were previously log-transformed (SLA, SRL, Pheight, LChl, LNC). The F and P values of the LMM analysis are also shown. 
All the trait values were previously scaled by log-transformation to calculate the hypervolumes (Lamanna and others 2014).

All these analyses were conducted in the $\mathrm{R}$ $2 \cdot 10 \cdot 0$ statistical platform ( $\mathrm{R}$ Development Core Team, 2011), using the packages "vegan" (Oksanen, 2013), "hypervolume" (Blonder and others 2014), 'nlme' (Pinheiro and others 2015) and 'FD' (Laliberté and Shipley 2011).

\section{Results}

\section{Functional trait variation along the aridity gra- dient}

We detected high trait variability among the species composing the different sampled communities. The first PCA axis accounted for $37.6 \%$ of overall variation (Appendix S2) and was related in one extreme (negative values) with species showing high values of traits representative of the resource acquisition strategy (SLA, Lsize, SRL, LChl, Pheight, and $\mathrm{LN})$. At the opposite extreme (positive values), there were species with high values of traits representative of the resource-conservation strategy (LDMC, SDMC, WD, RDMC, TMDr and $\delta^{13} \mathrm{C}$ ). The communities inhabiting wetter zones (Hum For and Rip For) were dominated by species having high values of leaf size (Lsize), specific leaf area (SLA), specific root length (SRL), leaf chlorophyll (LChl), plant height (Pheight) and plant cover (Pcover) (Fig. 2, Appendix S2 and S3). In contrast, the arid and semi-arid shrublands (SArid and Arid Shr) were dominated by species with high values of stem wood density (SWD) and root dry matter content (RDMC) (higher in the semi-arid shrubland). Interestingly, the arid shrublands showed the lowest values of leaf dry matter content (LDMC) and the highest values of leaf nitrogen concentration (LNC) (close to those found in the riparian forest). For most of the measured traits, the DrySH For showed intermediate values or values similar to those of the arid and semi-arid shrublands. The only exception was SDMC, which had its highest value in the DrySH For (Fig. 2 and Appendix S3).

\section{Functional diversity along the aridity gradient}

We calculated the hypervolume space for each of the five habitats, considering five plant dimensions (leaf, stem and root morphology, leaf chemical and plant size). Since we measured several traits for each of these dimensions, we finally used a single PCA axis for each of them, which individually explained a large proportion of the total variance. We used these first axes of the PCA to determine the hypervolumes of the woody plant communities along the aridity gradient.

The results from the n-dimensional hypervolume approach show that the functional space was greatest for the riparian forest (Fig. 3A) in the five plant dimensions (leaf, stem, root, leaf chemical and plant size). In addition, after standardising for species richness, the functional space showed significant variation along the aridity gradient, the hypervolume being significantly greater for the wet habitats than for the dry habitats $(P<0.001$; Fig. 3B).

The functional richness (FRich) was significantly higher in the Rip For (Fig. 4) supporting the results from the niche hypervolume (Fig. 3B). However, across-habitat differences for both FEve and FDiv were marginally significant $(P<0.06)$, due to the divergent Hum For values (Fig. 3).

The degree of overlapping among the hypervolumes of the different communities was variable, ranging from 0 to $40 \%$ (Fig. 5). The overlap was greater between the dry environments (Arid Shr and $\boldsymbol{S A r i d} \boldsymbol{S h r}$ ) and lower when comparing these dry environments with the riparian forest. The lower values of the hypervolumes and the greater overlap among them in the driest environments indicate that the trait space occupation of different species is much less variable than in the wet zones. In spite of the high functional space overlap between dry environments, the percentage of similarity in species composition was lower than 20\% (Fig. 5 ), while the similarity indices for species composition between the wet zones were higher (40\%). As expected, species composition was very different among the wet (riparian and humid forest) and dry habitats (dry forest and arid and semi-arid shrublands).

\section{Hypervolume space is dependent on functional dimensions}

The hypervolume variations were different when we considered the plant organs or dimensions separately (Appendix S4 and Fig. 6) in comparison to the whole hypervolume described above. Thus, the dry communities showed the greatest functional space for the leaf morphology (Arid Shr $=19.5 \mathrm{sd}^{3}$; Fig. 6A) and chemical dimensions (SArid Shr = $0.98 \mathrm{sd}^{3}$; Fig. 6C), followed by the wet communities in both cases. However, the wet communities showed the highest values for the root dimension ( Rip For $=2.93 \mathrm{sd}^{3}$ and Hum For $=1.85 \mathrm{sd}^{3}$; Fig. 6B). The dry semihumid forest displayed the smallest functional spaces in all cases.

\section{Discussion}

\section{Functional trait variation along the regional ari- dity gradient}

In this study, we have detected a consistent variation of several components of the functional trait structure (composition and diversity of functional traits; Mouillot and others 2011) in several Medite- 


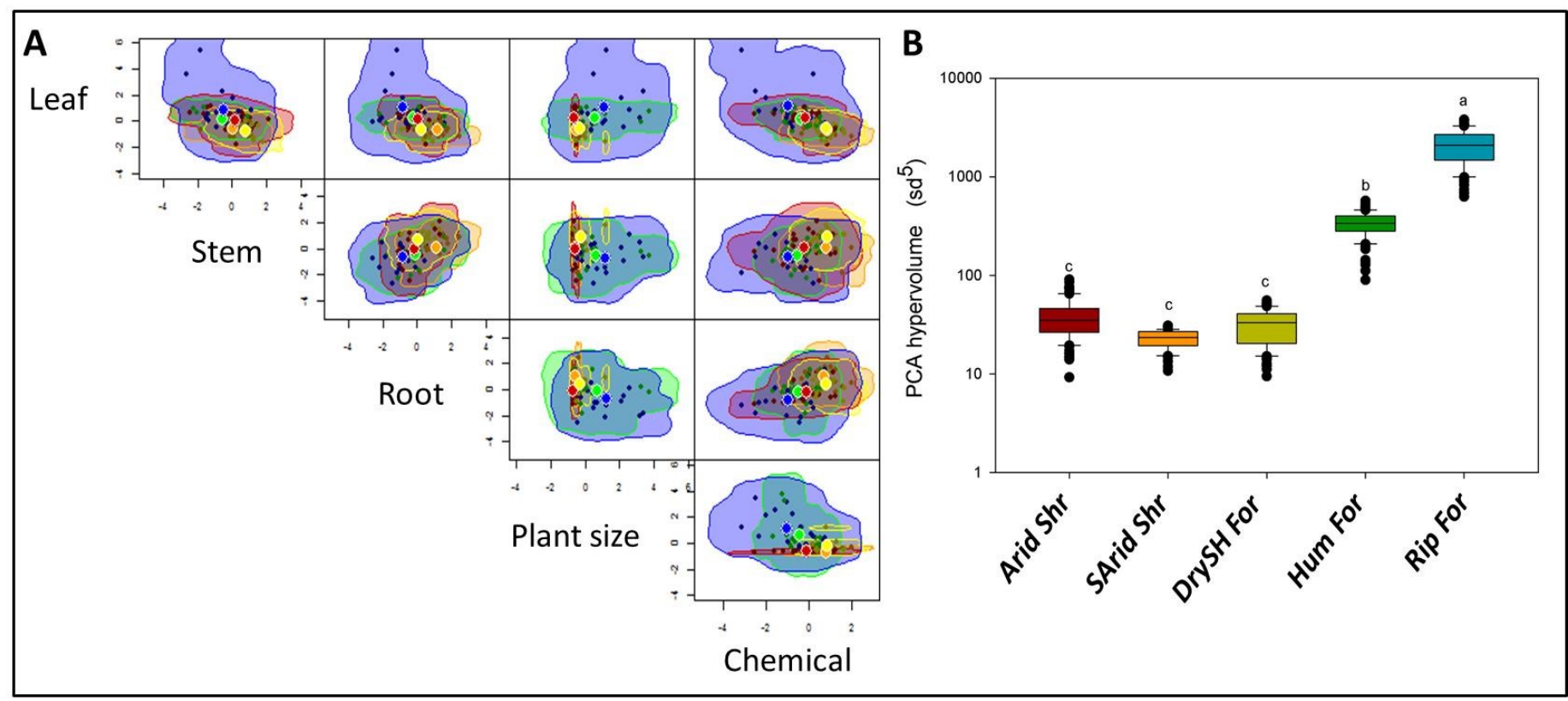

Figure 3. A) Estimated five-dimensional hypervolumes for the five habitats (see also Fig. 1). Each plant dimension was based on the first PCA axis of the different traits belonging to this dimension (Table 1). B) Size of the hypervolume of the five habitats along the regional gradient of water stress obtained by 100 randomised communities composed by 12 species from the total pool of each aridity zone. The line inside the box represents the median value, the box limits are the 25th and 75th percentiles, error bars show 10th and 90th percentiles, and filled symbols show outliers. Different letters indicate significant differences $(\mathrm{P}<0.05)$ among habitats according to a one-way ANOVA $(\mathrm{P}<0.001)$. Arid Shrublands -red-. Semiarid Shrublands -orange-, Dry Semihumid Forest -yellow-, Humid Forest green-, Riparian Forest -blue-.

rranean woody plant communities over a regional environmental gradient. This provides useful insights about the effects of aridity as a main driver of plant community assembly in Mediterranean environments. Our results show that the variation in plant traits was strongly related to the plant economics spectrum theory, a notion broadly accepted at both the local (Freschet and others 2010; de la Riva and others 2016a,b; but see Wright and SuttonGrier 2012) and global scale (Wright and others 2004). On the one hand, communities present in wet habitats (e.g. riparian and humid forest habitats) were dominated by fast-growing, acquisitive species (with high values of SLA, LChl, and plant size). These functional traits allow species to compete for space and light, which have been usually identified as the main limiting factors in productive ecosystems (Poorter and Markesteijn 2008; Bernard -Verdier and others 2012). On the other hand, plant communities inhabiting dry habitats (arid and semiarid shrublands) showed - in general - traits related to a drought tolerance strategy, such as small plant size, lower values of leaf size and SLA, and higher stem wood density (that is, slow growth rates and evergreen, sclerophyllous leaves). The general pattern obtained for the studied communities is consistent with previous studies in Mediterranean woody plant species at a local scale (Cornwell and Ackerly, 2009; de la Riva and others 2016a), where trait variation seemed to be related to the trade-off between conservation and acquisition of resources. Our results highlight the importance of water res- triction as a major driver of functional trait distribution in Mediterranean environments at a larger (regional) spatial scale.

\section{Variation in functional diversity and niche fun- ctional space along the regional aridity gradient}

We have documented here a consistent variation in functional space (hypervolumes) along a regional gradient of aridity, with smaller hypervolumes in more stressful environments. These results are in accordance with previous studies that found lower

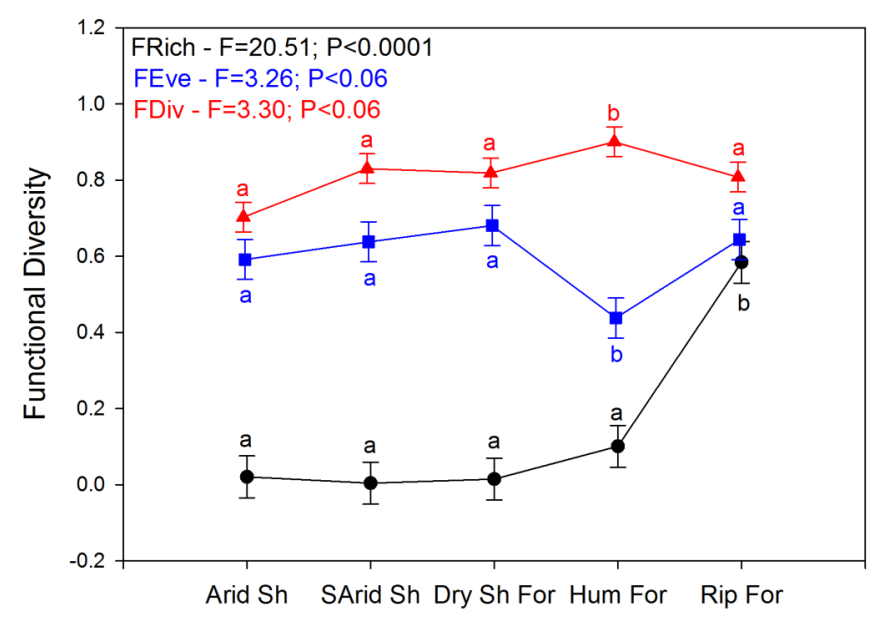

Figure 4. Differences in the functional diversity indexes (FRich: Richness, FEve: Evenness and FDiv: Divergence) among zones. Different letters denote significant differences between habitats (Tukey's test) 
functional diversity under more stressful climatic conditions (Kleidon and Mooney 2000; Reu and others 2011). In dry conditions, woody plants may exhibit different sets of functional traits (Jacobsen and others 2008; Grubb and others 2015), but this diversification of strategies is limited within the range of viable traits that allow plants to persist in this arid environment (de la Riva and others 2016b). Thus, water scarcity limits the establishment of species that are not physiologically able to tolerate such abiotic constraints, reducing the range of functional traits. For example, water limitation would be expected to act as a filter, excluding from these environments fast-growing species (with a more exploitative strategy) and limiting the functional space to more conservative functional traits (Cornwell and Ackerly 2009; de la Riva and others 2016a). The main differences along the gradient were due to the increase in functional trait variability in wetter zones (higher FRich), reflecting the niche space variations among the species present in the different arid zones.

Multiple functional traits may be correlated due to evolutionary or biophysical constraints and trade-offs and hence represent meaningful syndromes or strategies (Reich and others 2003). Thus, the different traits and dimensions used show some correlations (see Appendix S2), which could limit our assessments, such a result of the lack of volume from the potential functional space that is not occupied by our traits (Díaz and others 2016). Still, the concentration into five dimensions and the lumpiness within that plane reflect the major trait range and functional roles that are relevant to estimate a wide range of the functional niche occupation.

In wetter zones (riparian and humid forests), where no water limitation exists, another secondary filter probably operates (Cingolani and others 2007). For example, in riparian and humid forests, the dense shade created by the most-dominant fast-

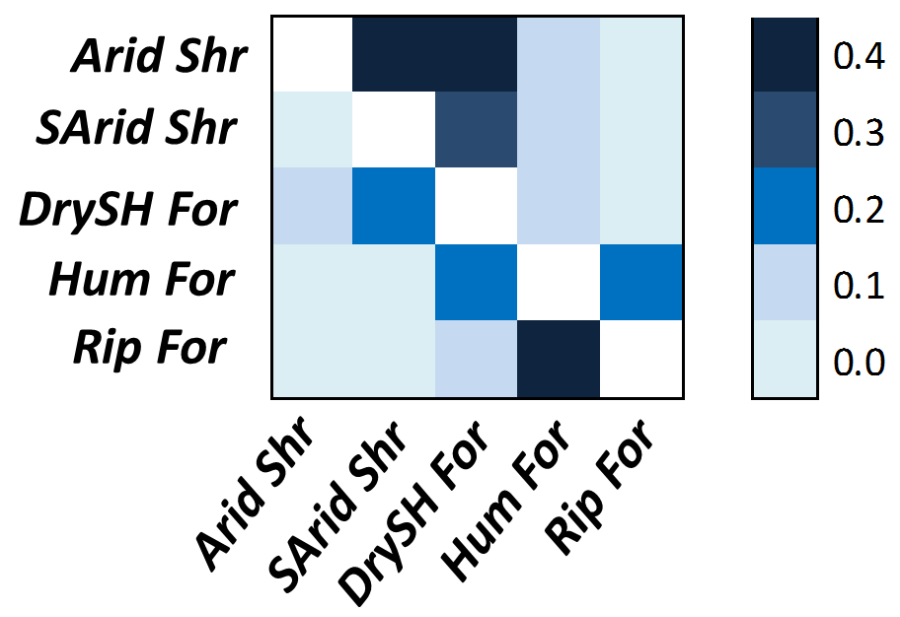

Figure 5. Values of the Sørensen similarity index calculated for the functional niche space (above the diagonal) and for the vegetation composition (below the diagonal). growing species induces greater competition for light among them (de la Riva and others 2016a), promoting the acquisitive strategy as the most advantageous for coping with a competitive exclusion (Reich and others 1992; Mayfield and Levine 2010). However, in spite of that strong interspecific competition, we found larger functional space in the wet communities studied here. This could be due to several factors. First, the larger functional space of the communities inhabiting wetter habitats could result from niche differentiation (Ackerly and Cornwell 2007), that promotes the coexistence of species with different traits (Stubbs and Wilson 2004; Grime 2006). For example, the existence of different plant adaptations to cope with light competition, like lianas (i.e. Hedera helix or Smilax aspera) or plants with phyllodes (i.e. Ruscus aculeatus), is noteworthy. Secondly, in productive habitats, water availability and competition for light may promote the spatial aggregation of taller, resource-acquisitive species, facilitating the persistence of smaller and less-competitive species in the remaining open areas (Gross and others 2013). Thus, the gap spaces resulting from different disturbance processes (e.g. river floods or canopy tree death) could be relevant to the functional heterogeneity of these habitats (Biswas 2010), promoting the colonisation by some light-demanding species (i.e. Cistus salvifolius, Pistacia lentiscus or Rhamnus lycioides). As expected, similar patterns were observed when comparing the two approaches used in this study (functional richness and hypervolume approaches), although the kernel density (hypervolume) seemed to show greater sensitivity for functional trait space occupation among study zones than the convex hull model (FRich). However, these differences became weaker or disappeared when functional diversity (instead of the FRich and hypervolume approach) was calculated taking into account species abundances (FEve and FDiv). This could be explained because the range of functional trait variation of dominant species is similar between zones and there are no drastic changes in term of species dominance and species evenness for functional trait variation (Villéger and others 2010). As we previously observed, these results reinforce the strong influence of water restriction not only in functional trait distribution, but also in the range of functional trait variation of the dominant species. The marginal differences found in the functional diversity of Hum For could be due to the differences in the functional space occupied by the dominant species that share this environment with two contrasting growth form strategies; for instance tree species from genus Quercus $(Q$. canariensis and $Q$. suber) and vines (Hedera helix or Smilax aspera), which would increase the functional divergence to the detriment of evenness.

The communities of the dry environments (Arid Shr, SArid Shr and DrySH For) showed 

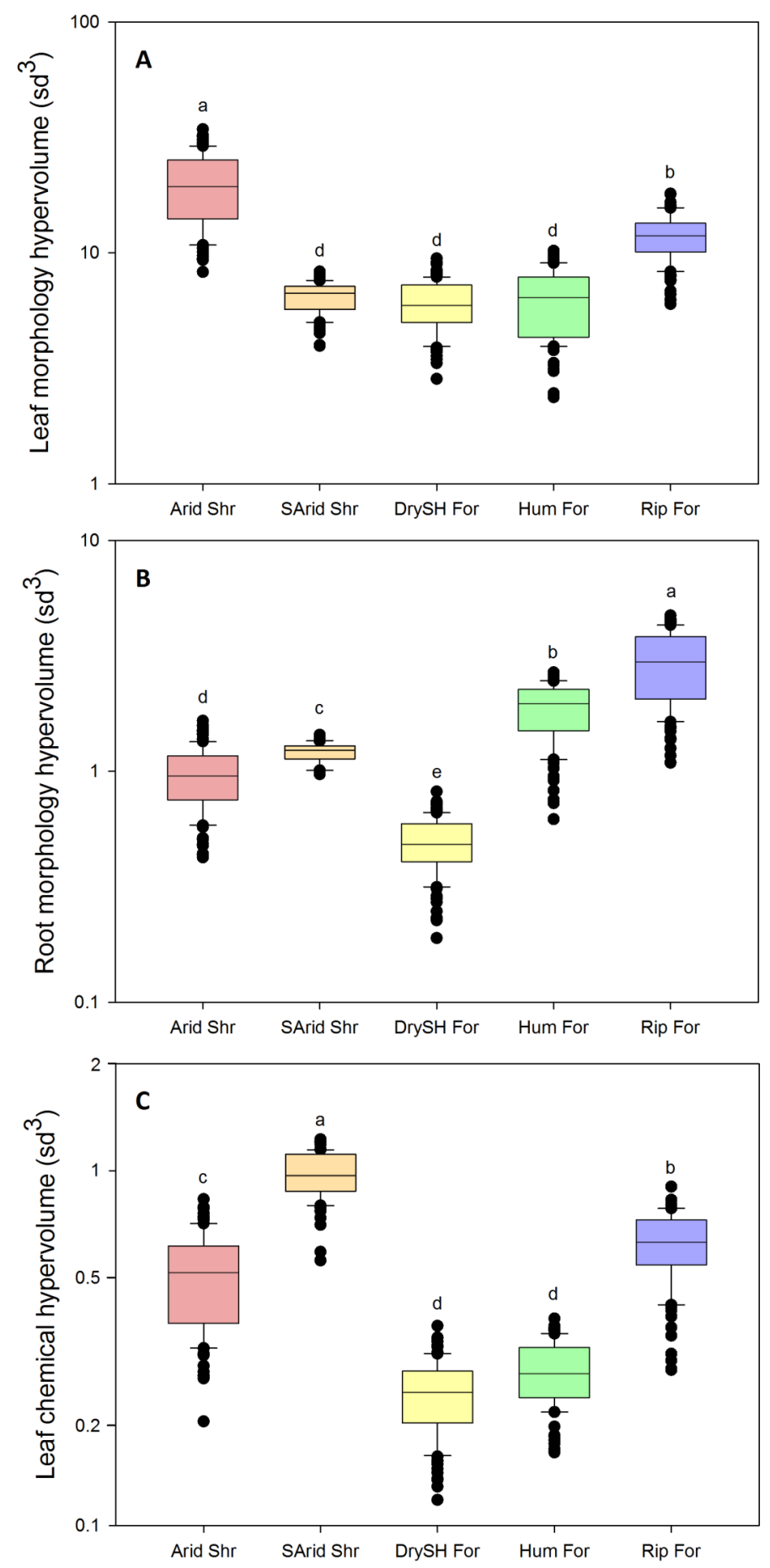

Figure 6. Size of the hypervolume variations for each plant dimension (leaf and root morphology and leaf chemical traits) in the five habitats studied along the regional gradient of water stress. Different letters indicate significant differences $(P<0.05)$ among habitats, according to post hoc multiple pairwise comparisons (Tukey's test). The ANOVA results were significant in all cases

smaller hypervolumes with a higher degree of overlap between them, in contrast to the communities from the wet environments. These results suggest that trait space occupation in wetter zones is much more variable than in the driest zones. Further, the hypervolumes of the dry communities showed higher overlaps in terms of functional structure than in terms of species composition (Fig. 5), and wet environments shared higher niche overlap for spe- cies similarity than for functional structure. This suggests that there is a strong pressure for a similar resource-use strategy (Mason and others 2011), and supports the idea of aridity in Mediterranean regions as a potential convergence force clustering trait values at a regional scale (Gross and others 2013). In contrast, the wetter habitats (Hum and Rip For) showed higher similarity in species composition than in functional structure, which implies higher functional over-dispersion among these zones for the unshared species. Similar results were found by de Bello and others (2007), who suggested that the mechanisms related to community functional assembly do not necessarily match those promoting species coexistence. Hence, species richness indices may not be replaced always by indices of functional diversity (de Bello and others 2007).

\section{Mismatch of niche functional spaces between dif- ferent plant dimensions}

The trends obtained for the multidimensional trait hypervolume were different when considering the plant dimensions separately. We found greater niche space in arid and semi-arid shrublands for the leaf morphology and chemical dimensions, respectively, while the wetter environments (Hum For and Rip For) showed greater hypervolumes for the root dimension. The lack of a general and congruent pattern when comparing results of different trait dimensions (i.e. leaf and root morphology) suggests that the functional diversity can depend largely on the niche axis considered (see also Loranger et al. 2016b) (although these differences could be also attributed to the proportion of variance that was not included in the PCA axes of the different plant dimensions, especially in the case of leaf chemical). Our results agree with those obtained by Mason and others (2011), who found dissimilar niche overlap for different traits related to similar aspects of plant strategy. As it has been hypothesized, the strength of filtering depends on the traits studied (Grime 2006), because filtering could affect differently the range of variation of each plant organ or dimension (de Bello and others 2013; Laughlin and others 2014). Therefore, within the range of viable functional traits that persist under particular environmental conditions, the diversification of successful strategies tends to exist (de la Riva and others $2016 \mathrm{~b}$ ), promoting species coexistence through the complementary uses of resources (Stubbs and Wilson 2004). For example, the soils of arid shrublands are very shallow and poor in nutrients (data not shown), which could be a strong constraint to greater root trait diversification (greater root hypervolume); however, at the leaf level different growth forms related to different resource-uptake and drought-survival strategies coexist (e.g. evergreen, and summer-deciduous shrubs; Gálmes and others 
2005; Jacobsen and others 2008; Grubb and others 2015). Hence, according with the 'limiting similarity principle' (MacArthur and Levins 1967), some divergence of strategies exist as a result of resource partitioning (Cornwell and Ackerly 2009), but without compromising (necessarily) in the same way all plant dimensions and within the range of viable trait values for these particular abiotic conditions.

The lower functional diversity detected in the communities of the most stressful and arid habitats reflected a relatively homogeneous functional structure dominated by shrubs with a predominant resource-conservative strategy (see also Jacobsen and others 2008). However, other studies based on aboveground traits found a lower functional diversity in more benign conditions (Pakeman 2011; de Bello and others 2013). These contradictory results could arise from the comparison of different scales and different diversity indices or growth forms (i.e. herbaceous/woody species), which do not necessarily support the global patterns (de Bello and others 2007; Funk and Cornwell 2013). In the light of our results, the trait dimension considered could be also an important factor to take into account (Loranger and others 2016b). In this regard, most of the studies linking plant functional diversity and environmental factors are biased to above-ground traits, often ignoring the root dimension. Therefore, our results reinforce the importance of considering a multidimensional approach, which implies the inclusion of root attributes in the calculations of functional diversity, to better understand the role of aridity as a driver of community functional structure in Mediterranean environments.

\section{Conclusions}

Our study highlights the trait hypervolume approach as a useful tool to understand community assembly patterns and quantify species niches over a broad regional scale. In addition, our results show that the wettest ecosystems serve as a reservoir of functional diversity, mainly constituted by species with a predominantly acquisitive strategy and a deciduous leaf habit. By contrast, the greater functional diversity in the leaf dimension detected in the dry habitats studied may offer a wide range of possible adaptations to cope with water stress (Stubbs and Wilson 2004; Mason and others 2005), which could imply greater resilience in the face of increasing aridity. The fact that particular dimensions of the functional community structure respond differently along the aridity gradient makes this kind of study relevant to the modelling of vegetation responses to the ongoing climate change. However, more research along regional gradients worldwide is needed to better understand the community assembly process and to forecast the consequences of in- creased aridity (according to IPCC 2013 predictions) for ecosystem functions and services.

\section{Acknowledgements}

This study was funded by the Spanish MEC projects DIVERBOS (CGL2011-30285-C02-01 and C02-02), ECO-MEDIT (CGL2014-53236-R), RESTECO (CGL2014-52858-R) and DECAFUN (CGL2015-70123-R), the Andalusian ANASINQUE project (PGC2010-RNM-5782), the Life + Biodehesa Project (11/BIO/ES/000726), the and European FEDER funds. CV was supported by the European Research Council (ERC) Starting Grant Project 'Ecophysiological and biophysical constraints on domestication in crop plants' (Grant ERC-StG-2014-639706-CONSTRAINTS). Thanks are due to Emilio Retamosa and Vicky Schwarzer from the Cabo de Gata Natural Park, for field assistance and plant classification. Isotopic analysis was carried out in the LIE (EBD-CSIC) and analysis of leaf $\mathrm{N}$ in the SCAI of the University of Córdoba. Dr. David Walker revised the English.

\section{References}

Ackerly DD, Cornwell WK. 2007. A trait-based approach to community assembly: partitioning of species trait values into within-and amongcommunity components. Ecol Lett 10: 135-145.

Arnell, NW. 1999. Climate change and global water resources. Glob Environ Change, 9: S31-S49.

Bernard-Verdier M, Navas ML, Vellend M, Violle C, Fayolle A, Garnier E. 2012. Community assembly along a soil depth gradient: contrasting patterns of plant trait convergence and divergence in a Mediterranean rangeland. J Ecol 100: 1422-1433.

Biswas SR, Mallik AU. 2010. Disturbance effects on species diversity and functional diversity in riparian and upland plant communities. Ecology 91: 28-35.

Blonder B, Lamanna C, Violle C, Enquist BJ. 2014. The n-dimensional hypervolume. Global Ecol Biogeogr 23: 595-609.

Bréda N, Huc R, Granier A, Dreyer E. 2006. Temperate forest trees and stands under severe drought: a review of ecophysiological responses, adaptation processes and long-term consequences. Ann For Sci 63: 625-644.

Canfield R H. 1941. Application of the line interception method in sampling range vegetation. J Forestry 39: 388-394.

Carmona CP, de Bello F, Mason NW, Lepš J. 2016. Traits without borders: integrating functional diversity across scales. Trends Ecol Evol 31: 382394.

Cingolani AM., Cabido M, Gurvich DE, Renison D, Díaz S. 2007. Filtering processes in the assembly of plant communities: Are species presence and abundance driven by the same traits? J Veg Sci 18: 911-920. 
Cornwell WK, Ackerly DD. 2009. Community assembly and shifts in plant trait distributions across an environmental gradient in coastal California. Ecol Monogr 79: 109-126.

Cornwell WK, Schwilk DW, Ackerly DD. 2006. A traitbased test for habitat filtering: convex hull volume. Ecology, 87: 1465-1471.

Craine, JM, Wedin DA, Chapin FS, Reich PB. 2003. Relationship between the structure of root systems and resource use for 11 North American grassland plants. Plant Ecol 165: 85-100.

de Bello F, Lepš J, Lavorel S, Moretti M. 2007. Importance of species abundance for assessment of trait composition: an example based on pollinator communities. Community Ecol 8: 163-170.

de Bello F, Lavorel S, Lavergne S, Albert CH, Boulangeat I, Mazel F, Thuiller W. 2013. Hierarchical effects of environmental filters on the functional structure of plant communities: a case study in the French Alps. Ecography 36: 393-402.

de la Riva EG, Pérez-Ramos IM, Tosto A, NavarroFernández CM, Olmo M, Marañón T, Villar R. 2016a. Disentangling the relative importance of species occurrence, abundance and intraspecific variability in community assembly: a trait-based approach at the whole-plant level in Mediterranean forests. Oikos 125: 354-363.

de la Riva EG, Tosto A, Pérez-Ramos IM, NavarroFernández CM, Olmo M, Anten NP, Marañón T, Villar R. 2016b. A plant economics spectrum in Mediterranean forests along environmental gradients: is there coordination among leaf, stem and root traits? J Veg Sci, 27: 187-199.

Díaz S, Kattge J, Cornelissen JH, Wright IJ, Lavorel S, Dray S, and others. 2016. The global spectrum of plant form and function. Nature 529:167-171.

Engelbrecht BMJ, Comita LS, Condit R, Kursar TA, Tyree MT, Turner BL, Hubbell SP. 2007. Drought sensitivity shapes species distribution patterns in tropical forests. Nature 447: 80-82.

Freschet GT, Cornelissen JH, Van Logtestijn RS, Aerts R. 2010. Evidence of the 'plant economics spectrum' in a subarctic flora. J Ecol 98: 362-373.

Funk JL, Cornwell WK. 2013. Leaf traits within communities: context may affect the mapping of traits to function. Ecology 94: 1893-1897.

Gálmes J, Cifre J, Medrano H, Flexas J. 2005. Modulation of relative growth rate and its components by water stress in Mediterranean species with different growth forms. Oecologia 145: 21-31.

Garnier E, Lavorel S, Ansquer P, Castro H, Cruz P, Dolezal, J, Eriksson O, Fortunel C, and others. 2007. A standardized methodology to assess the effects of land use change on plant traits, communities and ecosystem functioning in grasslands. Ann Bot 99: 967-985.

Garnier E, Navas ML. 2012. A trait-based approach to comparative functional plant ecology: concepts, methods and applications for agroecology. A review. Agron Sustain Dev 32: 365-399.

Grime JP. 2006. Trait convergence and trait divergence in herbaceous plant communities: mechanisms and consequences. J Veg Sci 17: 255-260.

Gross N, Börger L, Soriano-Morales SI, and others.
2013. Uncovering multiscale effects of aridity and biotic interactions on the functional structure of Mediterranean shrublands. J Ecol 101: 637-649.

Grubb PJ, Marañón T, Pugnaire FI, Sack L. 2015. Relationships between specific leaf area and leaf composition in succulent and non-succulent species of contrasting semi-desert communities in southeastern Spain. J Arid Environ 118: 69-83.

Heberling JM, Fridley JD. 2012. Biogeographic constraints on the world-wide leaf economics spectrum. Global Ecol Biogeogr 21: 1137-1146.

Heywood VH.1995 (ed.). Global Biodiversity Assessment. Cambridge University Press, England.

Hutchinson GE. 1957. Cold Spring Harbour Symposium on Quantitative Biology. Concluding remarks, 22: 415-427.

IPCC. 2013. Climate change 2013: the physical scientific basis.WMO, UNEP.

Jacobsen AL, Pratt RB, Davis SD, Ewers FW. 2008. Comparative community physiology: Nonconvergence in water relations among three semi-arid shrub communities. New Phytol 180: 100-113.

Kleidon A, Mooney HA. 2000. A global distribution of biodiversity inferred from climatic constraints: results from a process-based modelling study. Global Change Biol 6: 507-523.

Klein CH. 2007. Lecture Notes for the Teaching Module Forest Inventory. Institute of Forest Management, Faculty of Forest Sciences and Forest Ecology. Georg August Universitat, DE, 164 p.

Kramer-Walter KR, Bellingham PJ, Millar TR, Smissen RD, Richardson SJ, Laughlin DC. 2016. Root traits are multidimensional: specific root length is independent from root tissue density and the plant economic spectrum. J Ecol 104: 1299 -1310

Laliberté E. 2017. Below-ground frontiers in trait-based plant ecology. New Phytol 213: 1597-1603.

Laliberté E, Shipley B. 2011. Measuring Functional Diversity (FD) From Multiple Traits, and Other Tools for Functional Ecology. 1.0-11.

Lamanna, C, Blonder B, Violle, C, and others 2014. Functional trait space and the latitudinal diversity gradient. Proc Natl Acad Sci USA 111: 1374513750.

Laughlin D C. 2014. The intrinsic dimensionality of plant traits and its relevance to community assembly. J Ecol 102: 186-193.

Laughlin DC, Leppert JJ, Moore MM, Sieg CH. 2010. A multi-trait test of the leaf-height-seed plant strategy scheme with 133 species from a pine forest flora. Funct Ecol 24: 493-501.

Loranger J, Blonder B, Garnier E, Shipley B, Vile D, Violle C. 2016b. Occupancy and overlap in trait space along a successional gradient in Mediterranean old fields. Am J Bot 103: 1050-1060.

Loranger J, Violle C, Shipley B, Lavorel S, Bonis A, Cruz P, Louault F, Loucougaray G, Mesléard F, Yavercovski N, Garnier E. 2016a. Recasting the dynamic equilibrium model through a functional lens: the interplay of trait-based community assembly and climate. J Ecol 104: 781-791.

MacArthur R, Levins R. 1967. The limiting similarity, convergence, and divergence of coexisting species. Amer Nat 101: 377-385. 
Maire V, Gross N, Börger L, and others. 2012. Habitat filtering and niche differentiation jointly explain species relative abundance within grassland communities along fertility and disturbance gradients. New Phytol 196: 497-509.

Mason NW, de Bello F, Doležal J, Lepš J. 2011. Niche overlap reveals the effects of competition, disturbance and contrasting assembly processes in experimental grassland communities. J Ecol 99: 788796.

Mason NW, Mouillot D, Lee WG, Wilson JB. 2005. Functional richness, functional evenness and functional divergence: the primary components of functional diversity. Oikos 111: 112-118.

Mayfield MM, Levine JM. 2010. Opposing effects of competitive exclusion on the phylogenetic structure of communities. Ecol Lett 13: 1085-1093.

Mokany K, Roxburgh, SH. 2010. The importance of spatial scale for trait-abundance relations. Oikos 119: 1504-1514.

Mouillot D, Villéger S, Scherer-Lorenzen M, Mason NW. 2011. Functional structure of biological communities predicts ecosystem multifunctionality. PloS one, 6:, e17476.

Navarro-Fernández CM, Pérez-Ramos IM, de la Riva EG, Vera JR, Roumet C, Villar R, Marañón T. 2016. Functional responses of Mediterranean plant communities to soil resource heterogeneity: a mycorrhizal trait-based approach. J Veg Sci 27: 1243-1253.

Oksanen, J, Blanchet FG, Kindt R, Legendre P, Minchin PR, O'Hara RB., Oksanen MJ. 2013. Package 'vegan'. Community ecology package, version, 2 (9).

Padilla FM, Pugnaire FI. 2007. Rooting depth and soil moisture control Mediterranean woody seedling survival during drought. Funct Ecol 21: 489-495.

Pakeman RJ. 2011. Functional diversity indices reveal the impacts of land use intensification on plant community assembly. J Ecol 99: 1143-1151.

Pérez-Harguindeguy N, Díaz S, Garnier E, and others. 2013. New handbook for standardised measurement of plant functional traits worldwide. Aust $\mathbf{J}$ Bot 61: 167-234.

Pérez-Ramos IM, Roumet C, Cruz P, and others. 2012. Evidence for a "plant community economics spectrum" driven by nutrient and water limitations in a Mediterranean rangeland of southern France. J Ecol 100: 1315-1327.

Pinheiro J, Bates D, DebRoy S, Sarkar D and R Core Team. 2015. nlme: Linear and Nonlinear Mixed Effects Models. R package version 3.1-121, http://CRAN.R-project.org/package=nlme.

Poorter L, Markesteijn L. 2008. Seedling traits determine drought tolerance of tropical tree species. Biotropica 40: 321-331.

Reich PB, Walters MB, Ellsworth DS. 1992. Leaf lifespan in relation to leaf, plant, and stand characteristics among diverse ecosystems. Ecol Monogr 62: 365-392.

Reu B, Proulx R, Bohn K, Dyke JG, Kleidon A, Pavlick R, Schmidtlein S. 2011. The role of climate and plant functional trade-offs in shaping global biome and biodiversity patterns. Global Ecol Biogeogr
20: $570-581$.

Schimel DS, Braswell R, McKeown R, Ojima DS, Parton WJ, Pulliam W. 1996. Climate and nitrogen controls on the geography and timescales of terrestrial biogeochemical cycling. Global Biogeochem Cycles 10: 677-692.

Stubbs WJ, Bastow Wilson J. 2004. Evidence for limiting similarity in a sand dune community. J Ecol 92: 557-567.

Thuiller W, Lavorel S, Sykes MT, Araújo MB. 2006. Using niche-based modelling to assess the impact of climate change on tree functional diversity in Europe. Divers Distrib 12: 49-60.

Trabucco A, Zomer RJ. 2009. Global Aridity Index (Global-Aridity) and Global Potential EvapoTranspiration (Global-PET) Geospatial Database. CGIAR Consortium for Spatial Information. Published online, available from the CGIAR-CSI GeoPortal at: http://www.csi.cgiar.org

Villéger S, Mason NWH, Mouillot D. 2008 New multidimensional functional diversity indices for a multifa- ceted framework in functional ecology. Ecology 89: 2290-301.

Villéger S, Ramos Miranda J, Flores Hernández D, Mouillot D. 2010. Contrasting changes in taxonomic vs. functional diversity of tropical fish communities after after habitat degradation. Ecol Appl 20: 1512-22.

Violle C, Jiang L. 2009. Towards a trait-based quantification of species niche. J Plant Ecol 2: 87-93.

Violle C, Reich PB, Pacala SW, Enquist BJ, Kattge J. 2014. The emergence and promise of functional biogeography. Proc Natl Acad Sci USA 111: 13690-13696.

Wright IJ, Reich PB, Westoby M, Ackerly DD, Baruch $\mathrm{Z}$, Bongers, F, Cavender-Bares $\mathrm{J}$, and others. 2004. The worldwide leaf economics spectrum. Nature 428: 821-827.

Wright JP, Sutton-Grier A. 2012. Does the leaf economic spectrum hold within local species pools across varying environmental conditions? Funct Ecol 26: 1390-1398. 
1 Appendix S1. List of the 74 woody plant species, family, life habit and their presence/absence in the five aridity zones.

\begin{tabular}{|c|c|c|c|c|c|c|c|}
\hline Species & Family & Life habit & $\begin{array}{c}\text { Cabo de } \\
\text { Gata } \\
\text { (Arid Shr) }\end{array}$ & $\begin{array}{c}\text { Doñana } \\
\text { (SArid Shr) }\end{array}$ & $\begin{array}{c}\text { Sierra } \\
\text { Morena } \\
\text { (DrySH } \\
\text { For) } \\
\end{array}$ & $\begin{array}{c}\text { Alcornocales } \\
\text { (Hum For) }\end{array}$ & $\begin{array}{c}\text { Guadiato } \\
\text { River } \\
\text { (Rip For) }\end{array}$ \\
\hline Alnus glutinosa & Betulaceae & Tree & & & & & $x$ \\
\hline Anthyllis citysoides & Fabaceae & Shrub & $x$ & & & & \\
\hline Anthyllis terniflora & Fabaceae & Shrub & $x$ & & & & \\
\hline Arbutus unedo & Ericaceae & Arborescent-shrub & & & $x$ & $x$ & \\
\hline Armeria velutina & Plumbaginaceae & Shrub & & $x$ & & & \\
\hline Artemisia barririeri & Asteraceae & Shrub & $x$ & & & & \\
\hline Atractylis humilis & Asteraceae & Shrub & $x$ & & & & \\
\hline Ballota hirsuta & Lamiaceae & Shrub & $x$ & & & & \\
\hline Celtis australis & Cannabaceae & Tree & & & & & $x$ \\
\hline Cistus albidus & Cistaceae & Shrub & $x$ & & $x$ & & \\
\hline Cistus crispus & Cistaceae & Shrub & & & $x$ & & \\
\hline Cistus ladanifer & Cistaceae & Shrub & & & $x$ & & \\
\hline Cistus libanotis & Cistaceae & Shrub & & $x$ & & & \\
\hline Cistus monspeliensis & Cistaceae & Shrub & & & $x$ & & \\
\hline Cistus salvifolius & Cistaceae & Shrub & & & $x$ & $x$ & \\
\hline Coronilla juncea & Fabaceae & Shrub & $x$ & & & & \\
\hline Crataegus monogina & Rosaceae & Arborescent-shrub & & & & $x$ & $x$ \\
\hline Cytisus grandiflorus & Fabaceae & Shrub & & $x$ & & & \\
\hline Daphne gnidium & Malvaceae & Shrub & & & $x$ & & \\
\hline Ephedra fragilis & Ephedraceae & Shrub & $x$ & & & & \\
\hline Erica arborea & Ericaceae & Shrub & & & & $x$ & \\
\hline Erica scoparia & Ericaceae & Shrub & & $x$ & & & \\
\hline Ficus carica & Moraceae & Tree & & & & & $x$ \\
\hline Fraxinus angustifolia & Oleaceae & Tree & & & & & $x$ \\
\hline Fumana spidula & Violaceae & Shrub & $x$ & & & & \\
\hline Genista hirsuta & Fabaceae & Shrub & & & $x$ & & \\
\hline
\end{tabular}




\begin{tabular}{|c|c|c|}
\hline Halimium commutatum & Malvaceae & Shrub \\
\hline Halimium halimifolium & Malvaceae & Shrub \\
\hline Hedera helix & Araliaceae & Vine \\
\hline Helianthemum almeriensis & Malvaceae & Shrub \\
\hline Helianthemum syriacum & Malvaceae & Shrub \\
\hline Helichrysum stoechas & Asteraceae & Shrub \\
\hline Helycrissum picardii & Asteraceae & Shrub \\
\hline Hippocrepis scabra & Fabaceae & Shrub \\
\hline Juniperus phoenicea & Cupressaceae & Arborescent-shrub \\
\hline Launaea arborescens & Asteraceae & Shrub \\
\hline Lavandula multifida & Lamiaceae & Shrub \\
\hline Lavandula stoechas & Lamiaceae & Shrub \\
\hline Myrtus communis & Mirtaceae & Shrub \\
\hline Nerium oleander & Apocynaceae & Arborescent-shrub \\
\hline Phlomis fruticosa & Lamiaceae & Shrub \\
\hline Phlomis purpurea & Lamiaceae & Shrub \\
\hline Phyllirea angustifolia & Oleaceae & Arborescent-shrub \\
\hline Phyllirea latifolia & Oleaceae & Arborescent-shrub \\
\hline Pinus pinea & Pinnaceae & Tree \\
\hline Pistacia lentiscus & Anacardiaceae & Arborescent-shrub \\
\hline Pistacia terebinthus & Anacardiaceae & Arborescent-shrub \\
\hline Populus alba & Salicaceae & Tree \\
\hline Quecus cocifera & Fagaceae & Arborescent-shrub \\
\hline Quercus canariensis & Fagaceae & Tree \\
\hline Quercus ilex & Fagaceae & Arborescent-shrub \\
\hline Quercus suber & Fagaceae & Tree \\
\hline Rhamnus alaternus & Rhamnaceae & Shrub \\
\hline Rhamnus lycioides & Rhamnaceae & Shrub \\
\hline Rhododendron ponticum & Ericaceae & Shrub \\
\hline Rosa canina & Rosaceae & Shrub \\
\hline Rosmarinus officinalis & Lamiaceae & Shrub \\
\hline Rubus ulmifolius & Rosaceae & Vine \\
\hline
\end{tabular}

X

$x$

$\mathrm{x}$

x 


\begin{tabular}{|c|c|c|c|c|c|c|}
\hline Ruscus aculeatus & Asparagaceae & Shrub & & & $x$ & $x$ \\
\hline Salix atrocinerea & Salicaceae & Tree & & & & $x$ \\
\hline Sideritis pusilla & Lamiaceae & Shrub & $x$ & & & \\
\hline Smilax aspera & Smilacaceae & Vine & $x$ & & & $x$ \\
\hline Stauracanthus genistoides & Fabaceae & Shrub & & $x$ & & \\
\hline Teucrium charidemi & Lamiaceae & Shrub & $x$ & & & \\
\hline Teucrium fruticans & Lamiaceae & Shrub & & & & \\
\hline Thymelaea hirsuta & Malvaceae & Shrub & $x$ & & & \\
\hline Thymus hyemalis & Lamiaceae & Shrub & $x$ & & & \\
\hline Thymus mastichina & Lamiaceae & Shrub & & $x$ & & \\
\hline Ulex australis & Fabaceae & Shrub & & $x$ & & \\
\hline Ulex parviflorus & Fabaceae & Shrub & $x$ & & & \\
\hline Ulmus minor & Ulmaceae & Tree & & & & $x$ \\
\hline Viburnum tinus & Adoxaceae & Arborescent-shrub & & & $x$ & \\
\hline Vitis vinifera & Vitaceae & Vine & & & & $x$ \\
\hline Withania frutescens & Solanaceae & Shrub & $x$ & & & \\
\hline
\end{tabular}


3 Appendix S2. Principal components analysis (PCA) showing the plant economics spectrum, 4 from conservative (right) to fast-growing or acquisitive (left) species. 13 functional traits have 5 been sampled from 91 observations. (Arid Shrublands -red-, Semiarid Shrublands -orange-, Dry 6 Semihumid Forest -yellow-, Humid Forest -green-, Riparian Forest -blue-. SLA: Specific leaf 7 area; Lsize: Leaf area; LDMC: Leaf dry matter content; N: Leaf nitrogen concentration; LChl:

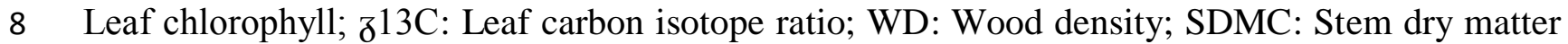
9 content; SRL: Specific root length; RDMC: Root dry matter content; TMDr: Root density; 10 Pheight: Plant height; Pcover: Plant cover.

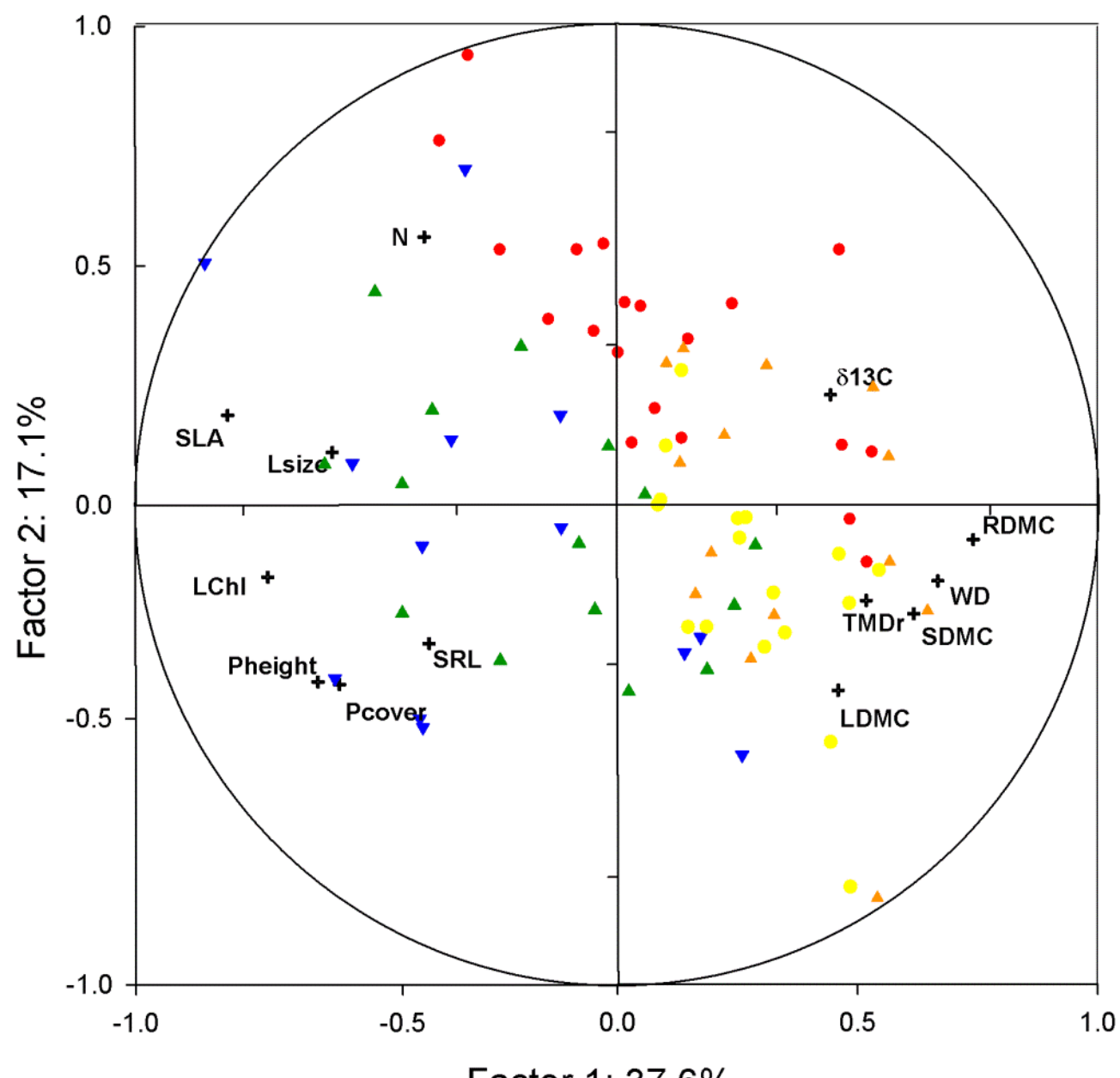

Factor $1: 37.6 \%$ 
12 Appendix S3. Mean values and standard errors (SE) and results of linear mixed models between aridity zones for functional traits 13 (species as random effect). Some traits have been log-transformed in order to fulfil statistic assumptions (*). Different letters indicate 14 significant differences $(P<0.05)$ among habitats, according to post hoc multiple pairwise comparisons (Tukey’s test).

\begin{tabular}{|c|c|c|c|c|c|c|c|c|c|c|c|c|c|c|c|c|c|c|c|c|c|c|}
\hline \multirow[b]{2}{*}{ Trait } & \multicolumn{4}{|c|}{ Arid Shr } & \multicolumn{4}{|c|}{ SArid Shr } & \multicolumn{4}{|c|}{ DrySH For } & \multicolumn{4}{|c|}{ Hum For } & \multicolumn{4}{|c|}{ Rip For } & \multirow[b]{2}{*}{ 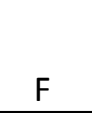 } & \multirow[b]{2}{*}{$P$} \\
\hline & Mean & & SE & & Mean & & SE & & Mean & & SE & & Mean & & SE & & Mean & & SE & & & \\
\hline Lsize* & 1.26 & \pm & 0.28 & c & 0.64 & \pm & 0.20 & c & 3.10 & \pm & 2.17 & $\mathrm{~b}$ & 11.8 & \pm & 2.17 & $\bar{a}$ & 26.6 & \pm & 10.6 & $a$ & 12.2 & $<0.001$ \\
\hline SLA* & 11.27 & \pm & 0.92 & $b c$ & 7.39 & \pm & 0.81 & $\mathrm{~cd}$ & 8.51 & \pm & 0.65 & c & 12.5 & \pm & 0.84 & $a b$ & 17.1 & \pm & 2.0 & a & 6.4 & 0.004 \\
\hline LDMC & 0.27 & \pm & 0.017 & $\mathrm{~b}$ & 0.38 & \pm & 0.01 & $a$ & 0.41 & \pm & 0.15 & $a$ & 0.35 & \pm & 0.05 & $a$ & 0.35 & \pm & 0.08 & a & 12.4 & $<0.001$ \\
\hline SWD & 0.51 & \pm & 0.02 & $a b$ & 0.53 & \pm & 0.08 & $a b$ & 0.59 & \pm & 0.08 & $a$ & 0.44 & \pm & 0.1 & $b$ & 0.43 & \pm & 0.11 & $b$ & 3 & 0.05 \\
\hline SDMC & 0.44 & \pm & 0.01 & $b$ & 0.46 & \pm & 0.06 & $b$ & 0.51 & \pm & 0.01 & $a$ & 0.41 & \pm & 0.07 & $b$ & 0.41 & \pm & 0.08 & $b$ & 8.3 & 0.04 \\
\hline SRL* & 5.16 & \pm & 0.36 & c & 13.4 & \pm & 1.84 & $a b$ & 10.8 & \pm & 0.87 & $b$ & 14.3 & \pm & 1.05 & $\mathrm{a}$ & 16.1 & \pm & 6.32 & a & 27.6 & $<0.001$ \\
\hline RDMC & 0.34 & \pm & 0.01 & bc & 0.43 & \pm & 0.01 & $\mathrm{a}$ & 0.39 & \pm & 0.01 & $a b$ & 0.36 & \pm & 0.02 & $\mathrm{~b}$ & 0.3 & \pm & 0.01 & c & 8.3 & 0.001 \\
\hline TMDr & 0.58 & \pm & 0.02 & $\mathrm{~b}$ & 0.8 & \pm & 0.04 & $\mathrm{a}$ & 0.66 & \pm & 0.02 & $\mathrm{~b}$ & 0.62 & \pm & 0.03 & $b$ & 0.57 & \pm & 0.04 & b & 7.7 & 0.005 \\
\hline $\mathrm{LN}^{*}$ & 2.63 & \pm & 0.14 & $a$ & 2.11 & \pm & 0.18 & $b c$ & 1.77 & \pm & 0.08 & $b c$ & 2.04 & \pm & 0.07 & $b c$ & 2.47 & \pm & 0.14 & $a b$ & 7.7 & 0.002 \\
\hline LChI* & 1066.4 & \pm & 94.8 & $\mathrm{~b}$ & 666 & \pm & 72.4 & c & 910.6 & \pm & 68.2 & $\mathrm{~b}$ & 1873 & \pm & 180.4 & $a$ & 2085.6 & \pm & 203.6 & a & 19.2 & $<0.001$ \\
\hline$\delta^{13} \mathrm{C}$ & -28.6 & \pm & 0.3 & & -27.6 & \pm & 0.5 & & -27.6 & \pm & 0.28 & & -28.9 & \pm & 0.28 & & -28.4 & \pm & 0.15 & & 2.7 & ns \\
\hline Pheight* & 0.61 & \pm & 0.67 & c & 0.87 & \pm & 0.13 & c & 1.91 & \pm & 0.27 & $b$ & 4.17 & \pm & 0.77 & $a$ & 5.52 & \pm & 0.8 & $a$ & 31.4 & $<0.001$ \\
\hline Pcover* & 0.83 & \pm & 0.16 & $\mathrm{~d}$ & 0.78 & \pm & 0.21 & $\mathrm{~d}$ & 4.39 & \pm & 1.68 & $\mathrm{C}$ & 12.1 & \pm & 4.27 & $\mathrm{~b}$ & 22.6 & \pm & 4.36 & a & 27.1 & $<0.001$ \\
\hline
\end{tabular}


17 Appendix S4. Estimated three-dimensional hypervolumes of the five aridity zones for each 18 independent plant dimension: (A) Leaf morphology, (B) Root morphology and (C) Leaf 19 chemical. Arid srhublands in red, Semi-Arid srhublands in orange, Dry-Semihumid forest in 20 yellow, Humid forest in green and Riparian forest in blue. SLA: Specific leaf area; Lsize: Leaf 21 area; LDMC: Leaf dry matter content; SRL: Specific root length; RDMC: Root dry matter

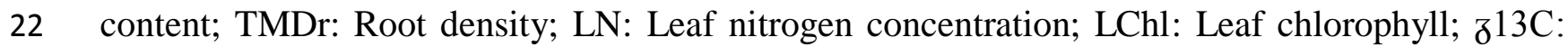
23 Leaf carbon isotope ratio.

24

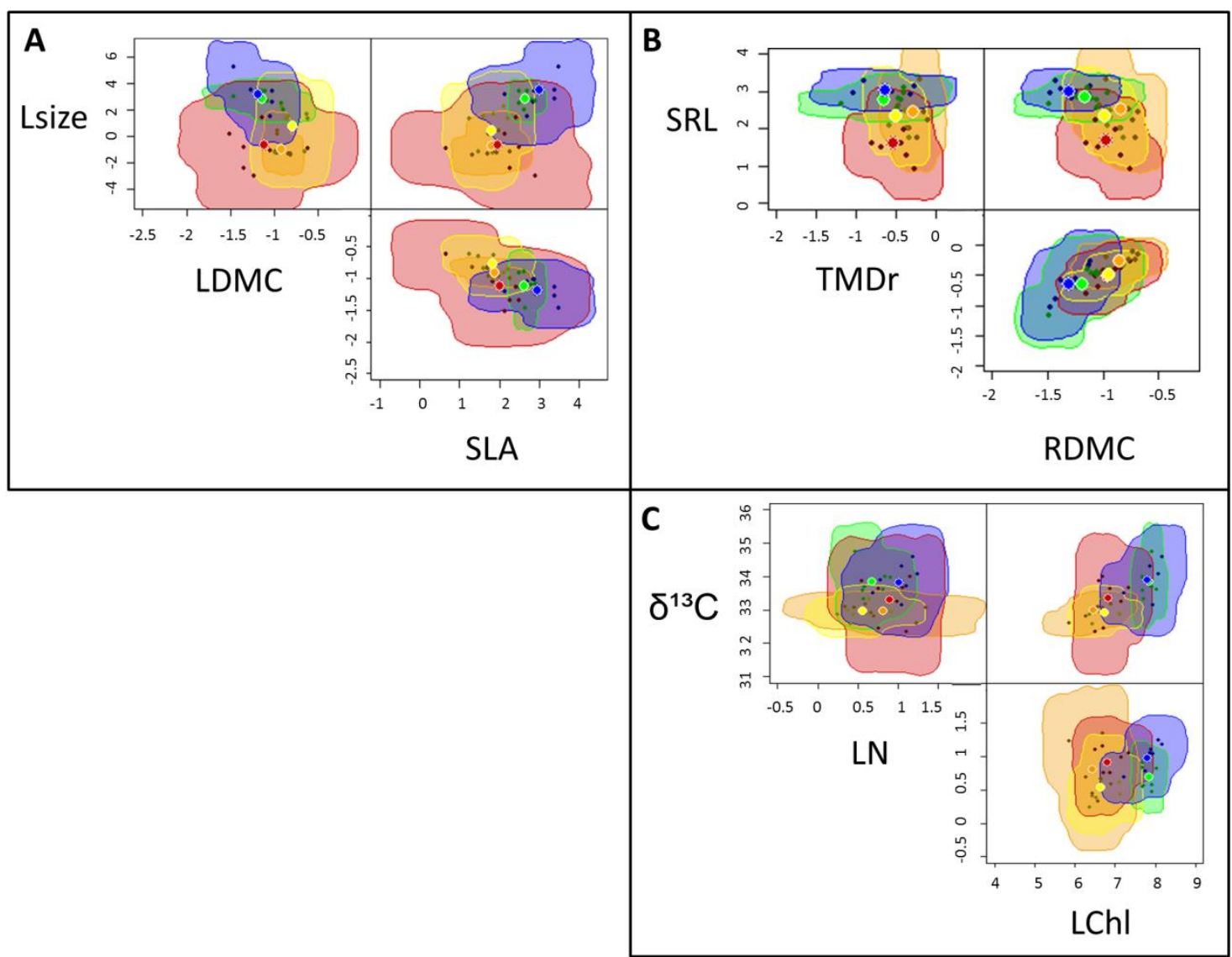

